\title{
Italian appeal court: a genetic predisposition to commit murder?
}

\author{
Francesca Forzano ${ }^{\star, 1}$, Pascal Borry ${ }^{2}$, Anne Cambon-Thomsen ${ }^{3}$, Shirley V Hodgson ${ }^{4}$, Aad Tibben ${ }^{5,6}$, \\ Petrus de Vries ${ }^{7,8}$, Carla van $\mathrm{El}^{9}$ and Martina Cornel ${ }^{9,10,11}$
}

\begin{abstract}
A few months ago, the controversial debate on connection between genetic variants and antisocial behaviour gained renewed prominence after the sentence of an Italian judge who decided to further reduce the prison sentence of a person convicted of murder by 1 year - from 9 to 8 years - because he was found to be a carrier of a few genetic variants thought to be associated with a predisposition to aggressiveness. We discuss the social implication of this view, the lack of evidence of the clinical utility of this test, and in particular the risks of offering susceptibility testing in the context of legal proceedings.
\end{abstract}

European Journal of Human Genetics (2010) 18, 519-521; doi:10.1038/ejhg.2010.31; published online 10 March 2010

Research in behavioural genetics has used molecular genetics research, linkage and association studies in an attempt to find which genes might be involved in behavioural phenotypes. In particular, some studies ${ }^{1-3}$ have focused on the heritability of 'increased impulsive' and 'antisocial' behaviours and have expanded the debate about how scientific findings such as these could affect criminal law and whether such information should mitigate criminal responsibility. ${ }^{4}$ These questions gained renewed prominence after the sentence of an Italian judge who decided to further reduce the prison sentence of a person convicted of murder by 1 year - from 9 to 8 years - because he was found to be a carrier of a few genetic variants that were thought to be associated with a predisposition to aggressiveness. ${ }^{5-7}$

\section{THE CASE}

The convicted man was an adult male affected by schizophrenia who was actively psychotic at the time of the crime, having discontinued his psychotropic medication against medical advice. He was found guilty at the first level of judgement and was given a reduced sentence (9 years) owing to his mental illness. At the appeal court, a new expert assessment took place, and genetic testing was requested by the defence. In particular, he was tested for variants within the MAOA, COMT, SCL6A4 and DRD4 genes. The judge based his sentence on the fact that the accused was affected by a mental disorder and that, because of the mental disorder, he was not fully capable of understanding the seriousness of his actions. The judge, however, reduced the sentence from 9 to 8 years, based on the fact that the accused had tested positive for genetic variants that made him particularly prone to be aggressive under stressful circumstances and therefore he was even more vulnerable because of that.

\section{MITIGATION OF RESPONSIBILITY}

To hold an individual criminally responsible for his actions, prosecutors have to prove not only that this individual committed the offences, but also that this individual had the required state of mind to be legally responsible for his acts. Therefore, lawyers of the defence will often question the criminal responsibility of their client based on the grounds of temporary or chronic insanity. These grounds will need the assessment of forensic psychiatrists. Worldwide sentencing guidelines for judges authorize punishment mitigations for offenders suffering from a reduced mental capacity; ${ }^{8}$ as a consequence, these criminal offenders might be subjected to compulsory confinement or hospitalization in psychiatric institution for treatment. According to Lewis, ${ }^{8}$ many judges may be reluctant to categorize a genetic predisposition for violence as a 'mental impairment', but also advance that this might 'serve the broad principle of justice that punishment of a crime be proportional to one's blameworthiness'.

\section{SCIENTIFIC EVIDENCE IS WEAK}

In the case we are discussing, the offender had received a reduced punishment based on his mental disorder. However, further reduction of his punishment based on the supposed establishment of a genetic basis conferring increased risks for violent behaviour raises various concerns. Given the state of the art in genetics, the possibility of using genetic variants to evaluate the actual mental capacity of a person at a given time is far from being established. Presently, genetic variants associated with schizophrenia do not add to the evaluation of the phenotype itself. We do not doubt that the physicians who reported on the forensic tests in this case operated in the most responsible way; however, scientists might have diversified opinions on the real predictive value and impact of these genetic variants. Little is known about the interactions with other possible, still unknown genetic variants and with the environmental factors that undoubtedly have a role in any behaviour. We believe that the specific context in which those analyses have been applied in itself makes these complex genetic evaluations especially prone to misinterpretations. The most questionable issue is the decision to request a susceptibility testing in the context of the legal

${ }^{1}$ Clinical Genetics Unit, Galliera Hospital, Genova, Italy; ${ }^{2}$ Research Fund Flanders, Centre for Biomedical Ethics and Law, Leuven, Belgium; ${ }^{3}$ UMR Inserm, Université Paul Sabatier - Toulouse III, U 558 Département d'épidémiologie et de santé publique, Faculté de médecine, Toulouse, France; ${ }^{4}$ Clinical Genetics Unit, St Georges Hospital, London, UK; ${ }^{5}$ Centre for Human and Clinical Genetics, Leiden University Medical Centre; ${ }^{6}$ Department of Clinical Genetics, Erasmus Medical Centre, Rotterdam, The Netherlands; ${ }^{7}$ Society for the Study of Behavioural Phenotypes (SSBP), University of Cambridge, Cambridge, UK; ${ }^{8}$ Developmental Psychiatry Section, University of Cambridge, Cambridge, UK; ${ }^{9} \mathrm{Clinical}$ Genetics \& EMGO Institute for Health and Care Research, VU University Medical Center, Amsterdam, The Netherlands; ${ }^{10}$ The Netherlands Genome Initiative's Centre for Society and Genomics, Nijmegen, The Netherlands and ${ }^{11}$ Societal Aspects Section of the CMSB, Leiden, The Netherlands

${ }^{*}$ Correspondence: Dr F Forzano, Clinical Genetics Unit, Galliera Hospital, via Volta 6, 16128 Genova, Italy. Tel: +39 0105634367 ; Fax: +39 01057481026 ;

E-mail: forzanof@galliera.it 
proceedings. The vast majority of these tests, if not all, are still purely research-based and have not received any formal evaluation in terms of clinical validity and utility. In our opinion, no susceptibility test should as yet be used in forensic or other judicial settings. The use of genetic tests in forensic contexts should be restricted to tests with proven clinical utility for the diagnosis of a disease relevant to the case judged.

\section{NOT PROBABILITIES BUT DIAGNOSIS}

A person should be judged on the basis of his actual condition and mental capacity at the moment of the act, independent of any theoretical predisposition to develop some disease or inappropriate behaviour - even assuming that there is really a link between abnormal behaviour and specific genetic variants. An individual should be judged on the basis of evidence-based information and not on the basis of probability interpretation. From the published data we know on the case, there was sufficient proof of evidence for the mental disorder of the accused, as he was actually suffering from schizophrenia and was acutely psychotic at the time of the crime, which was all determined on clinical grounds. We do not think that the possible aetiology of such a condition should make a difference to the evaluation of incapacity, but we do consider that the decision should be based on the objective nature and degree of the disorder, which may be independent of the genetic variants tested.

\section{IMPACT OF GENETIC INFORMATION FOR THE INDIVIDUAL AND SOCIETY}

Although genetic susceptibility information (as in the case for violence and aggression) has a probabilistic nature, this type of information often tends to be interpreted with a sense of determinism and by reduction of an individual to a 'genomic metaphysics.' It is crucial to avoid simplistic causal relations between genetic variants associated with violence or aggression and actual violent or aggressive behaviour. Whereas some people showing more aggressive or violent behaviour might have these particular gene variants, others will have the same variants despite being perfectly law-abiding citizens. It should be clear that there is no such thing as a 'criminal gene'. We should be aware that labelling individuals with a 'criminal gene' also leads to identifying them as being a risk to society. This type of stigmatization, based on weak evidence, is unacceptable. In addition, we believe that an over-emphasis on the role of genes in criminal behaviour might lead either to over-justification or to over-punishment - according to potentially differing interpretations. If the presence of susceptibility is interpreted as decreased responsibility, punishment might be lower. However, if citizens should be protected more against criminals who are more prone to recurrent crime, punishment might be higher. Both these standpoints would not have any rationale or guidance with current scientific evidence. We are particularly worried that the recent ruling, as well as similar ones that may have been previously deliberated, might constitute a dangerous precedent to which it will be possible to appeal in the future.

\section{INCOMPATIBILITY WITH THE CRIMINAL SYSTEM}

According to some social workers and legal professionals interviewed on this topic, ${ }^{4}$ the use of genetic susceptibility tests could be incompatible with a basic principle of the criminal justice system. Some practitioners believed that this could be considered as an infringement of the notion of presumption of innocence. As expressed by a participant: 'That's the other point isn't it, it's going to change the whole of, instead of innocent until proven guilty, you're guilty because you've got it. [=the increased risk]'. ${ }^{4}$ Therefore, it could as well be considered as an infringement of one's right to a fair trial. Moreover, participants envisaged that claims about genetic susceptibility for violence or aggressiveness could have implications for civil law as well. For example, it could inform the court's decisions with regard to the custody of children or affect decisions with regard to a minor's contact with a parent or family member. ${ }^{4}$

\section{CONCLUSION}

There is no scientific support to declare that gene variants, claimed to predispose to aggression, would make the carriers incapable of repressing an aggressive behaviour and thus unable to choose appropriate socially acceptable behaviours.

The context of this case made also the authors reflect on the expression 'mutation responsible for a disease' too often used by geneticists themselves, mostly in cases wherein a gene variant is the known cause of a disease. As a matter of fact, a gene never exerts any effect in terms of 'responsibility', and this word from a philosophical and legal register ${ }^{10}$ should not be used to describe biological mechanisms. There is a danger in using words that attribute to biology roles related to responsibility. The case discussed above may also underline the importance of words used by professionals to designate the effects of genes. When a judge is looking for responsibility and when geneticists themselves express the effect of genes in terms of responsibility, some confusion can be expected.

\section{CONFLICT OF INTEREST}

The authors declare no conflict of interest.

\section{ACKNOWLEDGEMENTS}

AC-T received funding from the European Community's Seventh Framework Programme (FP7/2007-2013) under grant agreement number 200754 (the GEN2PHEN project) and Grant agreement no. 223143 (the TECHGENE project) and from Grant agreement no. 2008302 (the EU Public Health project PHGEN II). Dr de Vries is chairman of the Society for the Study of Behavioural Phenotypes (SSBP), an international, interdisciplinary research group studying the learning and behavioural manifestations associated with genetic disorders.

The present letter has to be considered on behalf of the Public and Professional Policy Committee (PPPC) of the European Society of Human Genetics (ESHG). The members of the PPPC of ESHG in 2009-2010 were the following: Martina Cornel (Chair, Amsterdam, The Netherlands), Nurten Akarsu (Ankara, Turkey), Pascal Borry (Leuven, Belgium), Anne Cambon-Thomsen (Toulouse, France), Thoas Fioretos (Lund, Sweden), Francesca Forzano (Genoa, Italy), Shirley Hodgson (London, UK), Gyorgy Kosztolany (Pécs, Hungary), Ulf Kristoffersson (Lund, Sweden), Jan Lubinski, (Szczecin, Poland), Christine Patch (London, UK), Jorge Sequeiros (Porto, Portugal), Aad Tibben (Leiden, The Netherlands), Lisbeth Tranebjaerg (Copenhagen, Denmark), and Veronica van Heyningen (Edinburgh, UK).

\footnotetext{
1 Brunner HG, Nelen M, Breakefield XO, Ropers HH, van Oost BA: Abnormal behaviour associated with a point mutation in the structural gene for monoamine oxidase $A$. Science 1993; 262: 578-580.

2 Brunner HG: MAOA deficiency and abnormal behaviour: perspectives on an association. Ciba Found Symp 1996; 194: 155-164; discussion 164-7.

3 Caspi A, McClay J, Moffitt TE et al: Role of genotype in the cycle of violence in maltreated children. Science 2002; 297: 851-854.

4 Pieri E, Levitt M: Risky individuals and the politics of genetic research into aggressiveness and violence. Bioethics 2008; 22: 509-518.

5 Italian Sentence: RGAssise App. 6/2008 RGNR 1685/2007, RG. sent 5, dd 18 settembre 2009 http://www.personaedanno.it/cms/data/articoli/files/016153_resource1_orig.pdf.
} 
6 Feresin E: Lighter sentence for murderer with 'bad genes'. Nature 2009. Published online 30 October 2009, doi:10.1038/news.2009.1050 http://www.nature.com/news/2009/091030/ full/news.2009.1050.html.

7 Callaway E: Murderer with 'aggression genes' gets sentence cut. New Scientist 3 November 2009, http://www.newscientist.com/article/dn18098-murderer-withaggression-genes-gets-sentence-cut.html.
8 Lewis LS: The role genetic information plays in the criminal justice system. Arizona Law Rev 2005; 47: 519-549.

9 Mauron A: Essays on science and society. Is the genome the secular equivalent of the soul? Science 2001; 291: 831-832.

10 Jonas H: The Imperative of Responsibility: In Search of an Ethics for the Technological Age. University of Chicago Press: Chicago, USA, 1985, p 263. 